\title{
Effects of Rainfall and Underlying Surface on Flood Recession-The Upper Huaihe River Basin Case
}

\author{
Yashan Cheng $^{1,2} \cdot$ Yanfang Sang $^{1} \cdot$ Zhonggen Wang $^{1} \cdot$ Yuhan Guo $^{1,2} \cdot$ \\ Yin Tang ${ }^{1}$
}

Accepted: 5 September 2020/Published online: 2 November 2020

(C) The Author(s) 2020

\begin{abstract}
The effects of rainfall and underlying surface conditions on flood recession processes are a critical issue for flood risk reduction and water use in a region. In this article, we examined and clarified the issue in the upper Huaihe River Basin where flood disasters frequently occur. Data on 58 rainstorms and flooding events at eight watersheds during 2006-2015 were collected. An exponential equation (with a key flood recession coefficient) was used to fit the flood recession processes, and their correlations with six potential causal factors-decrease rate of rainfall intensity, distance from the storm center to the outlet of the basin, basin area, basin shape coefficient, basin average slope, and basin relief amplitude-were analyzed by the Spearman correlation test and the Kendall tau test. Our results show that $95 \%$ of the total flood recession events could be well fitted with the coefficient of determination $\left(R^{2}\right)$ values higher than 0.75 . When the decrease rate of rainfall intensity $(V i)$ is smaller than $0.2 \mathrm{~mm} / \mathrm{h}^{2}$, rainfall conditions more significantly control the flood recession process; when $V i$ is greater than $0.2 \mathrm{~mm} / \mathrm{h}^{2}$, underlying surface conditions dominate. The result of backward elimination shows that when $V i$ takes the values of $0.2-0.5 \mathrm{~mm} / \mathrm{h}^{2}$ and is greater than $0.5 \mathrm{~mm} / \mathrm{h}^{2}$, the flood recession process is primarily influenced by the basin's
\end{abstract}

Zhonggen Wang

wangzg@igsnrr.ac.cn

1 Key Laboratory of Water Cycle and Related Land Surface Processes, Institute of Geographic Sciences and Natural Resources Research, Chinese Academy of Sciences, Beijing 100101, China

2 University of Chinese Academy of Sciences, Beijing 100049, China average slope and basin area, respectively. The other three factors, however, indicate weak effects in the study area.

Keywords Backward elimination - China - Correlation test · Flood recession · Huaihe River Basin - Rainfall intensity

\section{Introduction}

Flooding is a natural phenomenon and will become a serious natural hazard when its water volume reaches a certain magnitude (Sayers et al. 2002; Alfieri et al. 2014). Floods frequently affect many basins and regions worldwide (Norbiato et al. 2007; Sampson et al. 2015; Curebal et al. 2016; Esposito et al. 2018). It is believed that the risk of floods at the global scale will increase greatly around 2050 , and the frequency of floods in 100 years will be doubled in $40 \%$ of the world because of the impact of climate change (Arnell and Gosling 2016).

A flooding event includes both the rising period and the recession period. The former is closely connected to rainfall, especially the maximum rainfall rate and the time to the centroid of a rainfall event (Shuster et al. 2008). Shuster and his colleagues proposed that a more precise time step was needed to note the rising period, which means that less precise temporal resolution data could not capture the variability in the stage that was to be expected with the short-term flow phenomena of the rising limb rate. The flood recession period, which typically is longer than $1 / 2$ of an entire flooding event, however, is more important for water use (Shorr 2000; Guan et al. 2014), because a flood could provide abundant water resources (Shao et al. 2009; Ahmad et al. 2014; Liu et al. 2015). 
Many studies, therefore, have explored the pattern of flood recession processes based on different physical factors. Rainfall and underlying surface conditions are the two main causal factors that influence the flood recession process in mountainous areas, on the precondition of weak human activity impacts (Khaleghi et al. 2011). Rainfall is the source of flood discharge and is critical in the flood recession process at different temporal resolutions. A higher-than-usual rainfall may lead to a rapid drop in the daily streamflow (and water level) (Ronchail et al. 2018). Similarly, rainfall is also a critical factor that causes changes in monthly flood recession processes (Mishra et al. 2014).

Different underlying surface conditions also cause differences in flood recession processes. Many studies have investigated the impact of land use/cover change (LUCC) on the flood recession process. For example, an increase in forest cover would lead to a substantial reduction in flood peak flows (Costa et al. 2003; Chang and Feng 2017). The conversion of cultivated land or grassland into urban land would increase the flood peak flow ( $\mathrm{Li}$ and Feng 2011). The amount and rate of flood recession in bare soil are smaller than those in straw-covered fields (Zhang et al. 2007). Terrain is also one of the factors that affect the flood recession process. Fan and Han (1991) conducted a slope experiment in a field and proposed that a $9^{\circ}$ slope is a critical point-slopes less than $9^{\circ}$ always had a greater impact on the recession flow, and when they exceeded $9^{\circ}$, this effect decreased quickly. Terrain indices are a typical representation of underlying surface factors. Jin et al. (2017) proposed that watersheds with high average topographic index values and their standard deviations have slower water falling rates. The shape of the river crosssection (Ye et al. 2019) and the geomorphological structure (Amit et al. 2002; Li et al. 2006) also have a great impact on the flood recession process.

The control factors of the recession process in various regions are also different. The basin recession process in the eastern part of the United States is greatly affected by the terrain factors, while the basin recession process in the western part is greatly affected by the soil factors (Patnaik et al. 2018). In northern Sweden (Karlsen et al. 2019), the basin topography is the main control factor of the recession process at a relatively high flow, while the basin area becomes important at relatively low flow.

In general, the flood recession process could be inferred by assuming a certain relationship between the aquifer water storage and its discharge. This relationship often refers to linear (Maillet 1905; Tallaksen 1995), exponential (Beven and Kirkby 1979), power functions (Wittenberg 1999; Li et al. 2010; Charron and Ouarda 2015), or other types. There are two key parameters of power-law storagedischarge function and it has been proven that the top five significant factors for recession are location, soil infiltration capacity, channel length, forest cover, and precipitation (Krakauer and Temimi 2011). The linear storage-discharge function originated from groundwater research; thus at present it is widely used in baseflow or dry season streamflow. In the baseflow recession process, the top four factors that have great influence on the key parameters are the mean annual precipitation, mean annual air temperature, soil type, and mean surface slope of a catchment (Beck et al. 2013).

Exponential decay in the recession process could be deduced with a linear storage and drainage relationship assumption. The exponential equation is also the most common fitting curve employed to fit the recession process (Saboe 1966; Amit et al. 2002; Shaw et al. 2013; Zhai et al. 2015). In the equation, a flood recession coefficient could be used to represent the characteristics of a flood recession process. It is also a key factor in flood forecasting in many hydrological models (Yan and Zhang 2014; Song et al. 2016; Kim and Han 2017).

Although the flood recession coefficient has a certain physical meaning (Young and Beven 1991), the physical change mechanism that determines the flood recession coefficient is still unclear. In hydrological models, it is regarded as a parameter that must be estimated using observed data where the phenomenon of "equifinality for different parameters" would easily lead to a "fake" flood recession coefficient. It is critical to clarify what causal factors determine the flood recession coefficient, and further control the flood recession process as a basis of reasonable and scientific management of water resources at the basin scale.

This study aimed to quantify the influence of rainfall and the underlying surface on flood recession processes, with a case in the upper Huaihe River Basin, China. We used the rainfall and runoff data over the period 2006-2015 at eight watersheds in the upper mountainous region of the Huaihe River Basin, an area with little influence by human activities. The underlying surface factors were extracted from the Digital Elevation Model (DEM) dataset with a spatial resolution of $250 \mathrm{~m}$. The Kendall tau test and Spearman rank-order correlation test were used to analyze the correlation between flood recession processes and rainfall, as well as underlying surface conditions. We also used backward elimination to quantify the relative importance of rainfall and underlying surface in flood recession processes.

This article is organized as follows. Section 2 presents the details of the study area and the data used. Section 3 introduces the method for fitting the flood recession process, two correlation tests, and backward elimination. The results are presented in Sect. 4. Following a discussion of 
the results and their implications in Sect. 5, the study's conclusions are presented in Sect. 6.

\section{Study Area and Data}

The Huaihe River Basin is situated between $30^{\circ} 55^{\prime}-$ $38^{\circ} 20^{\prime} \mathrm{N}$ and $111^{\circ} 55^{\prime}-120^{\circ} 45^{\prime} \mathrm{E}$, between the Yellow River and the Yangtze River, and spreads from the Tongbo Mountain and ends in the Yellow Sea (Fig. 1). We selected eight watersheds as the study area, which are in the mountainous and hilly areas around the edge of the Huaihe River Basin, with weak influences from human activities (red line in Fig. 1). Their area ranges from 17.9 to $1640 \mathrm{~km}^{2}$. It can be seen from Fig. 1 that the watershed elevation and relief amplitude of the eight watersheds are quite different. All eight watersheds belong to the monsoon climatic zone, the average annual temperature is $16.4{ }^{\circ} \mathrm{C}$ (from 2006 to 2015), and the average annual rainfall is $945 \mathrm{~mm}$ for the same period.

Owing to the monsoon and windward mountain terrain conditions, flooding has become the most serious natural hazard in the Huaihe River Basin (Wu et al. 2011; Chen et al. 2016; Zhang 2019). During the decade from 2006 to 2015, 58 flooding events occurred in the study area. Of these events, 20 occurred in the northern tributaries, 30 in

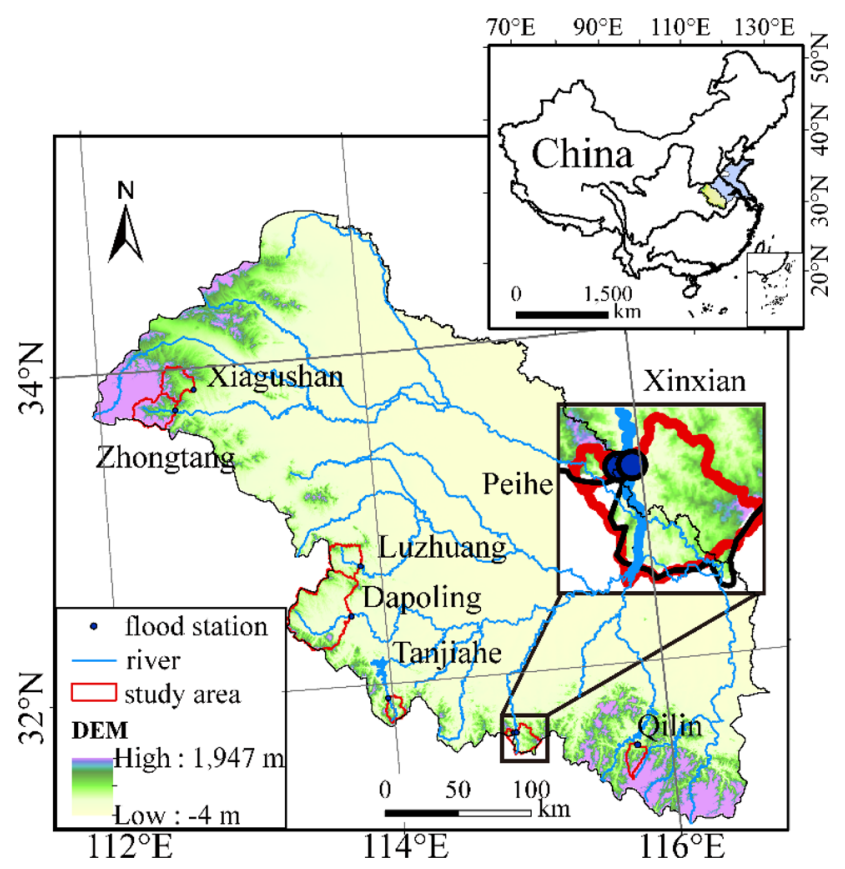

Fig. 1 Location and catchment outlets (shown as the flood stations in the figure) of the Huaihe River Basin study area. The eight catchments are indicated with a red line. The sky-blue area in the map inset in the upper right represents the Huaihe River Basin, and the area with DEM is part of the upper and middle regions of the Huaihe River Basin the southern tributaries, and eight in the mainstream. The peak flood ranged from 6.65 to $3370 \mathrm{~m}^{3} / \mathrm{s}$, and the maximum rainfall intensity changed from 0.22 to $16.4 \mathrm{~mm} / \mathrm{h}$.

All the rainfall data are recorded by gauges of the Hydrology Bureau at the Ministry of Water Resources of China and published in the Hydrological Data of Huaihe River Basin, Annual Hydrological Report (China 2006-2015). The time series is from 2006 to 2015. Since the time step of rainfall and runoff data recorded in the report are different, the original data must first be processed to the same temporal resolution. In this study, we unified the time step to $1 \mathrm{~h}$ for correspondence and comparison.

The rainfall data are recorded in the form of a rainfall depth over a period. For those periods of more than $1 \mathrm{~h}$, we denoted the rainfall at the first moment as 0 and denoted the rainfall per hour in the period as the average rainfall depth. The runoff record is expressed differently than the rainfall data. It represents a flow at the recorded moment. The recorded time, however, might not be on the hour. Therefore, to match it with the rainfall data, it is processed by simple linear interpolation to the nearest hour. Then an hourly rainfall and runoff data set between 2006 and 2015 was created. We extracted the data of the 58 rainfall and flooding events that occurred in the study area from this data set.

The underlying surface factors were computed by using the DEM from the Resource and Environment Science and Data Center (RESDC) ${ }^{1}$ with a spatial resolution of $250 \mathrm{~m}$. The DEM data were generated by resampling the data based on the latest SRTM-V4.1, and the source data are projected by a WGS84 ellipsoid.

\section{Methods}

First, the potential impact factors of recession process were extracted based on rainfall data and DEM. Then, we used exponential equation to fit the 58 recession processes collected, and derived 58 recession coefficients. Next, the Spearman rank-order correlation test and Kendall tau test were used to analyze the correlation between the potential impact factors and recession coefficient. Backwards elimination was further used to compare the importance of each potential impact factor on recession coefficient.

\subsection{Extracting the Impact Factors}

The flood recession process occurs after the maximum rain intensity. Two factors, the distance from the storm center to the outlet of the basin $(D)$ and the decrease rate of rainfall

\footnotetext{
${ }^{1}$ https://www.resdc.cn/Default.aspx.
} 
intensity $(\mathrm{Vi})$, therefore, were selected to describe the impact of the temporal and spatial characteristics of rainfall on the flood recession process. The $V i$ is defined as the average decrease rate of rainfall intensity from the moment when the maximum rainfall intensity occurs to the end of the rainfall event. In general, the rainstorm center always moves during a rainfall event. Therefore, the rainstorm center referred to in this article is the rainstorm center at the moment of the maximum rainfall intensity on the basin. The $D$ is the straight-line distance between the storm center and the outlet of the basin. Furthermore, four factors, namely the basin area (Area), basin shape coefficient (Bs), basin average slope (Slope), and basin relief amplitude $(R A)$ are selected to reflect the underlying characteristics of the eight basins.

The extraction of the underlying surface factors of the basin was based on the DEM data and processed by ArcGIS. First, we divided the Huaihe River Basin by DEM data into several small watersheds and then extracted their area. Next, we compared the extracted subwatershed area with the area recorded in the Hydrological Data of Huaihe River Basin, Annual Hydrological Report (China 2006-2015). If the data of the area extracted by DEM are consistent with those recorded in the report, it can be considered as correct. After that, confirmed width $(W)$ can be calculated by $W=$ Area/L. According to the equation $B s=W / L, R A=H \max -H \min$, the remaining underlying surface factor values can be calculated. Table 1 shows the value of the underlying surface factors.

Vegetation and soil are also critical underlying factors that affect the flood recession process. We collected two sets of LUCC data between 2005 and 2015 from RESDC, but it changed little across space; thus, land use was not considered an influencing factor in this study. Factors such as vegetation type, soil type, and soil texture were highly similar in the research area; thus, their influence on flood recession was almost the same in different watersheds, and we did not consider them in this study either.

\subsection{Recession Process Fitting}

In total, 58 unimodal flooding events occurred in the eight catchments between 2006 and 2015. It has been demonstrated that the peak flow and magnitude of floods are affected by rainfall volume and rainfall intensity (Gottschalk and Weingartner 1998; Zhang et al. 2005). Therefore, in order to reduce the impact of rainfall volume on the flood recession process simulation, the flood recession data were first normalized by dividing the flow that occurred after the peak flow by the peak flow and making the recession curve a decreasing curve with a peak value of 1 . Since the exponential equation is one of the common recession curve fitting equations, it was selected to fit each regression curve:

$y=e^{R t}$,

where $R$ is the recession coefficient $(1 / \mathrm{h})$, a negative value, $t$ is the recession time ( $t=0$ refers to the time of peak flow), and $R$ controls the shape of the recession curve, indicating the rate of the flood recession. The larger the $R$ is, the smoother the recession curve and the slower the recessional speed.

\subsection{Correlation Tests}

Because the correlation form between each factor and $R$ is unknown, two rank correlation tests, the Kendall tau test, and the Spearman rank-order correlation test, were used to evaluate their relationship. Both the Kendall tau test and Spearman rank-order correlation test are classic nonparametric statistical methods that use a monotone equation to evaluate the correlation between two variables (Spearman 1904; Kendall 1938). The correlation coefficient of the Spearman rank-order test is expressed by $\rho$, and the correlation coefficient of the Kendall tau test is expressed by $\tau$. Their values range from -1 to +1 , and 0 indicates that the two variables are uncorrelated. A positive value indicates a positive correlation, a negative value indicates a negative correlation, and a larger value indicates a stronger correlation.

\subsubsection{Spearman Rank-Order Correlation Test}

Assume that the two random variables are $X$ and $Y$, and the number of their elements is $N . X i$ and $Y i$ represent the $i$ th value of $X$ and $Y(1 \leq i \leq N)$. Sort $X$ and $Y$ in ascending or descending order at the same time to get two ranking sets $x$ and $y$. Use $x_{i}$ to represent the rank of $X i$ in $X$, and so do $y_{i}$. Then, calculate the Spearman rank-order correlation coefficient as follows:

$\rho=\frac{\sum_{i=1}^{N}\left(x_{i}-\bar{x}\right)\left(y_{i}-\bar{y}\right)}{\sqrt{\sum_{i=1}^{N}\left(x_{i}-\bar{x}\right)^{2} \sum_{i=1}^{N}\left(y_{i}-\bar{y}\right)^{2}}}$,

\subsubsection{Kendall Tau Test}

Assume that the two random variables are $X$ and $Y$, and the number of their elements is $N . X i$ and $Y i$ represent the $i$ th value of $X$ and $Y(1 \leq i \leq N)$. If is correct for any $i<j$ $\leq N$, then note it as a member of concordant pairs; otherwise, note it as a member of discordant pairs. Record the total number of concordant pairs as $N_{c}$ and the total number of discordant pairs as $N_{d}$. Then, calculate the Kendall tau correlation coefficient as follows: 
Table 1 Underlying surface features of the eight watersheds in the Huaihe River Basin, China

\begin{tabular}{llllrr}
\hline No. & Name & Area $\left(\mathrm{km}^{2}\right)$ & Basin shape coefficient $(B s)$ & Slope $\left({ }^{\circ}\right)$ & Relief amplitude $(R A)(\mathrm{m})$ \\
\hline 1 & Dapoling & 1640 & 0.8794 & 4.041 & 905 \\
2 & Luzhuang & 396 & 1.0796 & 3.567 & 592 \\
3 & Zhongtang & 485 & 0.8931 & 11.44 & 1703 \\
4 & Xiagushan & 354 & 0.6799 & 7.27 & 926 \\
5 & Tanjiahe & 152 & 0.6100 & 7.91 & 662 \\
6 & Peihe & 17.9 & 0.8903 & 7.37 & 605 \\
7 & Xinxian & 274 & 1.0512 & 10.56 & 881 \\
8 & Qilin & 185 & 0.3354 & & 1323 \\
\hline
\end{tabular}

$\tau=\frac{N_{c}-N_{d}}{N(N-1) / 2}$.

\subsection{Backward Elimination}

Backward elimination is an independent variable selection method for the linear regression model. In this study, it was used to compare the importance of each variable on $R$. First, enter all variables into the linear regression equation and then calculate the contribution of each variable and remove the variables that do not meet the confidence level. Next, calculate the contribution again, and repeat the steps until all the remaining variables meet the significance level. In this study, the confidence level is set at $95 \%$.

\section{Results}

All 58 flood recession processes were fitted by the exponential equation (Eq. 1). The results show that $95 \%$ of the total flood recession events can be well fitted with $R^{2}$ values greater than 0.75 . Table 2 shows the average $R$ and average $R^{2}$ of fitting results. All the average $R^{2}$ values exceed 0.8 , proving that the exponential equation matches these flood recession processes.

\subsection{Rainfall Factors' Impacts on Flood Recession Coefficient}

Figure 2 shows the effect of a single rainfall factor on $R$. It shows that the value of $V i$ is between 0 and $0.8 \mathrm{~mm} / \mathrm{h}^{2}$. In this $V i$ interval, the flood recession will be faster with the increase of $V i$, as shown in Fig. 2a. This relationship, however, seems discrete and not monotonous since $V i$ is not the only factor impacting the flood recession process. Some abnormal points can be seen in Fig. 2a. For example, $R$ in $V i$ between 0.2 and $0.5 \mathrm{~mm} / \mathrm{h}^{2}$ is much smaller than in other ranges of $V i$. Specifically, at the two points farmed in Fig. $2 \mathrm{a}, V i$ is only $0.4 \mathrm{~mm} / \mathrm{h}^{2}$, but $R$ is very small. The relationship between $D$ and $R$ should be positive, which is consistent with the trend shown in Fig. 2b. It also can be seen, however, that even if the rainstorm center is close to the basin outlet, a slower flood recession exists. From this viewpoint, the results obtained by analyzing the influence of a single factor are partially correct. $V i$ and $D$, therefore, must be considered in combination.

Table 2 Fitting result of the eight watersheds in the Huaihe River Basin, China

\begin{tabular}{|c|c|c|c|c|c|}
\hline No. & Name & Total number of flood events & Average recession coefficient $R$ & Range of $R^{2}$ & Average $R^{2}$ \\
\hline 1 & Dapoling & 8 & -0.0548 & $0.74-0.98$ & 0.90 \\
\hline 2 & Luzhuang & 6 & -0.1036 & $0.85-0.98$ & 0.94 \\
\hline 3 & Zhongtang & 4 & -0.1019 & $0.94-0.98$ & 0.96 \\
\hline 4 & Xiagushan & 10 & -0.1349 & $0.56-0.98$ & 0.86 \\
\hline 5 & Peihe & 4 & -0.2176 & $0.77-0.90$ & 0.86 \\
\hline 6 & Tanjiahe & 5 & -0.1118 & $0.88-0.99$ & 0.95 \\
\hline 7 & Xinxian & 14 & -0.0873 & $0.78-0.99$ & 0.92 \\
\hline 8 & Qilin & 7 & -0.1604 & $0.87-0.95$ & 0.92 \\
\hline
\end{tabular}




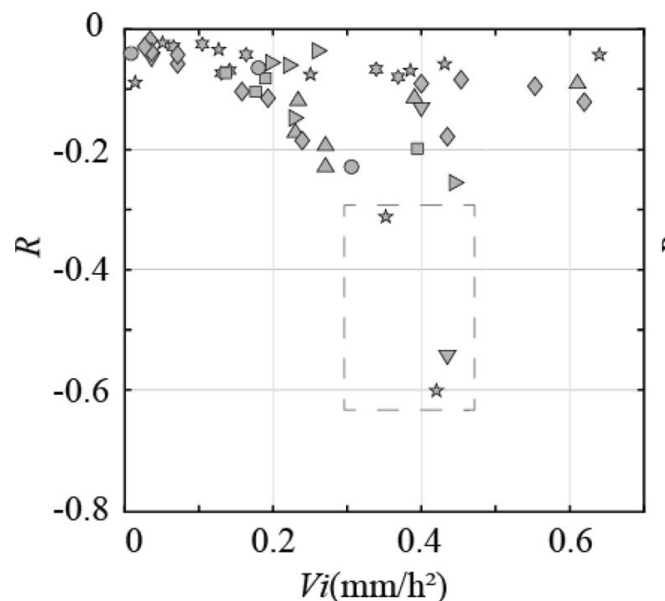

(a)

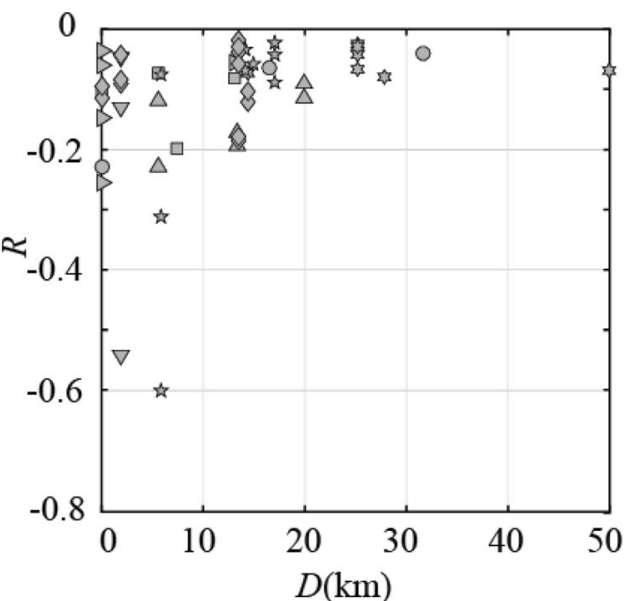

(b)
Fig. 2 Scatter plots of two rainfall factors versus flood recession coefficient $(R)$. The two rainfall factors are the decrease rate of rainfall intensity $(V i)$ and distance $(D) . R$ decreases with increase in $V i$

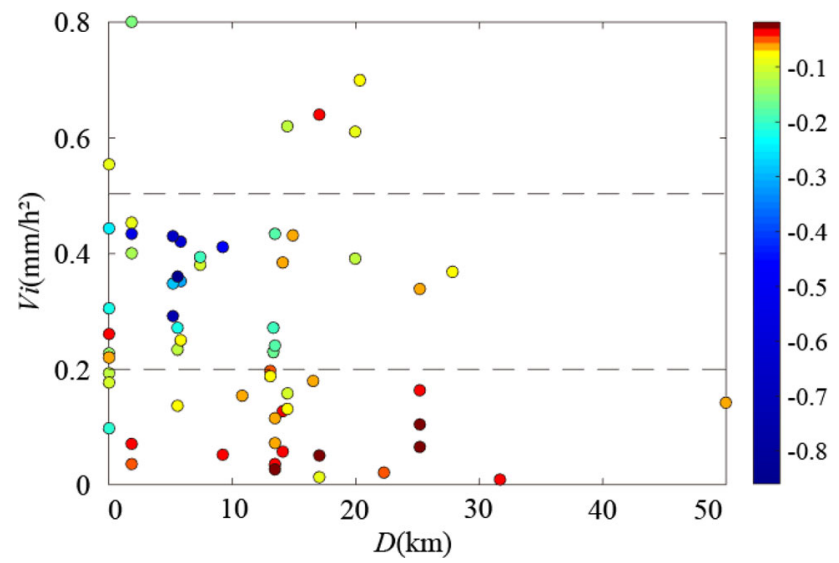

Fig. 3 Scatter plots of the decrease rate of rainfall intensity $(V i)$ and distance $(D)$ versus flood recession coefficient $(R)$. The color bar represents the value of $R$. When $V i$ is between 0.2 and $0.5 \mathrm{~mm} / \mathrm{h}^{2}$, the flood recession coefficient is much different from others

Considering the impact of $V i$ and $D$ simultaneously, $V i-$ $D-R$ change is plotted (Fig. 3). In Fig. 3, the vertical axis is $V i$, the horizontal axis is $D$, and the color bar represents the value of $R$. It can be seen that except for the flooding events $(D=0)$, when $V i$ is similar, the color of the points in the close horizontal line from left to right change from deep blue to yellow or dark red. This color change means that the farther the distance between the storm center and the outlet, the slower the recessional speed. The recession coefficient $R$ shows a clear division with the change of $V i$ and $D$. It is mostly red when $V i$ is less than $0.2 \mathrm{~mm} / \mathrm{h}^{2}$ (which indicates the recessional speed is slow), and blue when the $V i$ value is between 0.2 and $0.5 \mathrm{~mm} / \mathrm{h}^{2}$ (which indicates the recessional speed is much faster). It is mostly green and yellow, however, when $V i$ is greater than nonmonotonically (a) and increases with increase in $D$ nonmonotonically (b). The dash line in a shows some abnormal points with medium $V i$ and smaller $R$

$0.5 \mathrm{~mm} / \mathrm{h}^{2}$, indicating that the recessional rate changes slowly compared to the previous stage.

From the overall relationship of the data, under the same premise of a similar $D$, when $V i$ is less than $0.2 \mathrm{~mm} / \mathrm{h}^{2}, R$ is decreasing with the increase of $V i$, but when $V i$ is greater than $0.2 \mathrm{~mm} / \mathrm{h}^{2}, R$ is increasing with the increase of $V i$. It is difficult to say which part is abnormal. It could be explained, however, that in addition to rainfall, the underlying surface plays a pivotal role in the flood recession process.

\subsection{Underlying Surface's Impacts on Flood Recession Coefficient}

Since each watershed experienced more than one flooding event, for the convenience of analysis, an average value of $R$ in each watershed was calculated to explore the impact of the underlying factors on $R$ (Table 2). Figure 4 shows the graph of the average $R$ and the characteristics of the underlying surface condition factors.

Figure 4 shows that $R$ increases with Area, indicating that flood recession processes are faster in small watersheds than in big watersheds. This is consistent with our general perception. The confluence path of a large watershed is larger than the confluence path of a small watershed; therefore, flood recession processes in the large watershed will be slower.

As for the influence of the average slope of the watershed on $R$, there is a tendency that $R$ decreases as the slope increases. Steep slopes, therefore, increase the velocity of the flow, and the flood decreases quickly.

There is no significant relationship between $B s$ and $R$. The relationship between $R A$ and $R$ is also complex but a little positive, indicating that a greater $R A$ leads to a slower 
Fig. 4 Scatter plots of a Area; b basin shape coefficient $(B s)$; c Slope; and $\mathbf{d}$ relief amplitude $(R A)$ versus flood recession coefficient $(R)$. In this graph, $R$ increases with Area and $R A$, and decreases with $B s$ and Slope. The positive relationship between $R A$ and $R$ is not really conspicuous

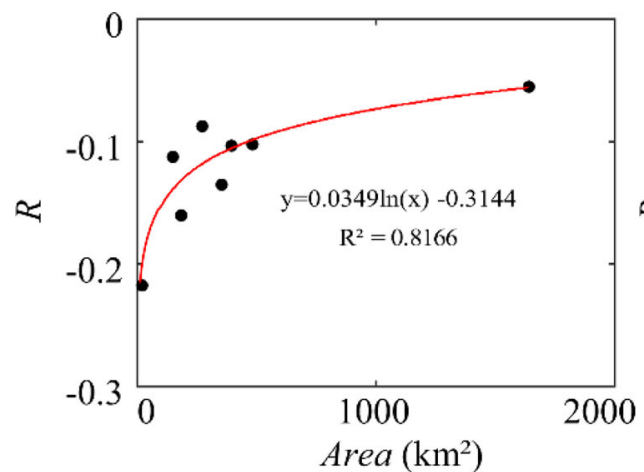

(a)

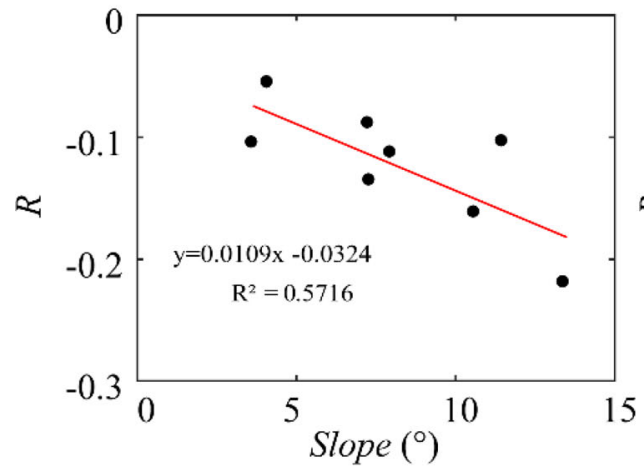

(c)

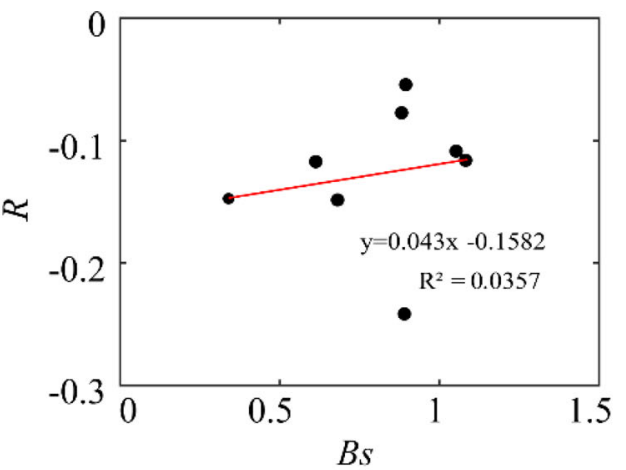

(b)

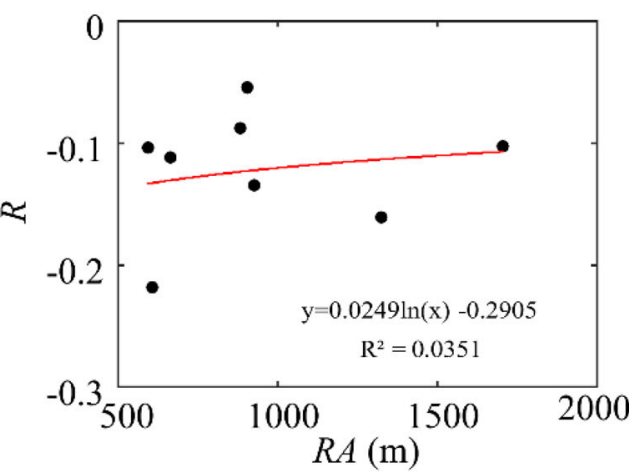

(d) recessional rate. Higher $R A$ may indicate that the terrain in the basin is more complicated. The path of the outflow might then be more tortuous, so the flood recession process becomes slower.

\subsection{Dominant Factors in Different Stage of $V i$}

According to the result of Sect. 4.1, the flooding events could be divided into three types by the value of $V i$. The first type is the floods with $V i$ less than $0.2 \mathrm{~mm} / \mathrm{h}^{2}$, the second type is the floods with $V i$ between 0.2 and $0.5 \mathrm{~mm} /$ $\mathrm{h}^{2}$, and the last type is the floods with $V i$ greater than $0.5 \mathrm{~mm} / \mathrm{h}^{2}$. The relationship between the recession coefficient and impact factors of the floods in each category was calculated by the Kendall tau test and the Spearman rankorder correlation test, and the results are shown in Table 3.
It shows that the correlation coefficient between watershed area and $R$ is positive, which is consistent with the results in Fig. 4. Similarly, the relationship between Slope, $V i, D$ and $R$ in Table 3 are also the same as that in Fig. 4. The difference of the sign of the correlation coefficient, however, indicates that the influence of $B s$ and $R A$ on $R$ differs at different ranges of $V i$. Not all of the results, however, satisfy the significance condition. Therefore, we cannot judge the relationship between the influencing factors and $R$ by the numbers in Table 3 alone. Focusing on correlation coefficients that satisfy the significance condition, $V i$ and $D$ have a great correlation with $R$ when $V i$ is less than $0.2 \mathrm{~mm} / \mathrm{h}^{2}$. The Kendall correlation coefficient and the Spearman correlation coefficient of $V i$ and $R$ are -0.368 and -0.528 . The Kendall correlation coefficient and the Spearman correlation coefficient of $D$ and $R$ is 0.280 and 0.396 . In type two, $R$ is

Table 3 Results of correlation tests of $R$ and the six impact factors

\begin{tabular}{|c|c|c|c|c|c|c|c|c|c|}
\hline \multicolumn{4}{|c|}{ Type } & \multirow{2}{*}{$\begin{array}{l}\begin{array}{l}\text { Area } \\
\left(\mathrm{km}^{2}\right)\end{array} \\
0.177\end{array}$} & \multirow{2}{*}{$\begin{array}{l}\begin{array}{l}\text { Basin shape } \\
\text { coefficient }(B s)\end{array} \\
0.120\end{array}$} & \multirow{2}{*}{$\frac{\text { Slope }\left(^{\circ}\right)}{-0.126}$} & \multirow{2}{*}{$\begin{array}{l}\begin{array}{l}\text { Relief amplitude } \\
(R A)(\mathrm{m})\end{array} \\
0.091\end{array}$} & \multirow{2}{*}{$\begin{array}{l}\text { Decrease rate of rainfall intensity } \\
(\mathrm{Vi})\left(\mathrm{mm} / \mathrm{h}^{2}\right) \\
-0.368^{*}\end{array}$} & \multirow{2}{*}{$\begin{array}{l}\text { Distance } \\
(D)(\mathrm{km})\end{array}$} \\
\hline 1 & $V i<0.2$ & $\tau$ & $R$ & & & & & & \\
\hline & & $\rho$ & $R$ & 0.266 & 0.164 & -0.183 & 0.156 & $-0.528 * *$ & $0.396^{*}$ \\
\hline \multirow[t]{2}{*}{2} & $0.2 \leq V i<$ & $\tau$ & $R$ & 0.266 & 0.124 & $-0.337 *$ & -0.082 & -0.157 & 0.156 \\
\hline & 0.5 & $\rho$ & $R$ & 0.334 & 0.170 & $-0.419 *$ & -0.156 & -0.201 & 0.192 \\
\hline \multirow[t]{2}{*}{3} & $V i \geq 0.5$ & $\tau$ & $R$ & 0.552 & -0.276 & 0.0 & 0.690 & -0.067 & 0.467 \\
\hline & & $\rho$ & $R$ & 0.754 & -0.406 & -0.058 & $0.812 *$ & -0.086 & 0.657 \\
\hline
\end{tabular}

*Indicates that the correlation is significant at $\alpha=0.05$ (two-tailed) and $* *$ indicates that the correlation is significant at $\alpha=0.01$ (two-tailed) 
Table 4 Normalized coefficients of the factors of fitting results (confidence level $=95 \%$ )

\begin{tabular}{|c|c|c|c|c|c|c|c|}
\hline Type & & $\begin{array}{l}\text { Area } \\
\left(\mathrm{km}^{2}\right)\end{array}$ & $\begin{array}{l}\text { Basin shape } \\
\text { coefficient }(B s)\end{array}$ & Slope $\left(^{\circ}\right)$ & $\begin{array}{l}\text { Relief } \\
\text { amplitude }(R A) \\
(\mathrm{m})\end{array}$ & $\begin{array}{l}\text { Decrease rate of rainfall } \\
\text { intensity }(V i)\left(\mathrm{mm} / \mathrm{h}^{2}\right)\end{array}$ & $\begin{array}{l}\text { Distance } \\
(D)(\mathrm{km})\end{array}$ \\
\hline 1 & $V i<0.2$ & & 0.414 & & & -0.348 & 0.274 \\
\hline 2 & $0.2 \leq V i<0.5$ & & & -0.342 & & & \\
\hline 3 & $V i \geq 0.5$ & 0.760 & & & & & \\
\hline
\end{tabular}

closely related to underlying surface condition factors, especially the average slope of the watershed. The Kendall correlation coefficient and the Spearman correlation coefficient of Slope and $R$ are - 0.337 and - 0.419. In type three, $R$ has a close connection with $R A$ of the watershed, the Spearman correlation coefficient between them is 0.812 .

In summary, in the first type, $R$ has a strong correlation with rainfall, in the second type, $R$ has a strong correlation with underlying surface factors, and the average slope of the watershed is the factor most closely related to $R$. Although $R$ is also closely related to underlying surface condition factors in the third type, the main role in this type is played by $R A$ of the watershed.

To quantify the influence of each factor on $R$, backward elimination analysis was used to calculate the coefficient of the six factors and $R$, where confidence level of $95 \%$ was considered. Table 4 shows the fitting results of those meeting the confidence level. Since the unit and magnitude of each factor are different, Table 4 only shows the normalized coefficients. It indicates that if we calculate $R$ by backward elimination, different dominate factors are found in different types. In type one, $R$ is controlled by both rainfall and underlying surface conditions. Among them, the two rainfall factors $V i$ and $D$ impact $R$ greatly, and their normalization coefficients are -0.348 and 0.274 , respectively. In this type, the main underlying surface factor $B s$ controls $R$, and the normalization coefficient is 0.414 . Compared with the results of the correlation analysis, the results of backward elimination show that $B s$ also has a big impact on $R$, but this effect was ignored in the correlation analysis. In type two, Slope has the main effect on $R$, and its normalized coefficient is -0.342 . This is consistent with the results of the correlation analysis. In type three, Area has the main effect on $R$, and its normalized coefficient is 0.760 . Compared with the results of the correlation analysis, the fitting results show that $R A$ has no significant impact on $R$.

\section{Discussion}

From the results obtained in Sect. 4, we find that the flood recession process is controlled by rainfall, basin average slope, and basin shape, which are similar to the results reported in Song et al. (2016). The significance of watershed area, however, is different in different situations in the study area in the flood recession process, which differs from the studies in Zillgens et al. (2007). Zillgens et al. (2007) indicated that the hydrographs at the larger scales exhibited significantly attenuated recession behavior than in smaller catchments in all bimodal event cases-this behavior could be related to a nested relationship among the watersheds, which did not exist in this study. Since our study did not include random factors such as human activities, the results should also be applicable to other basins with similar natural conditions.

Comparing the results in Tables 3 and 4, it can be found that although sometimes $R A$ has a strong relationship with $R$, this relationship is not a major impact factor after backward elimination. It can be explained as follows. The fitting curve in Fig. 4 shows that the connection between $R A$ and $R$ is more chaotic than the other underlying surface factors with $R$. From Table 3, we can see that the relationship between $R A$ and the flood recession coefficient varies with positive and negative correlations in different situations. The uncertain correlation relationship indicates that $R A$ is not a critical causal factor of change in $R$. $R A$, therefore, was removed after the backward elimination analysis.

$V i=0.2 \mathrm{~mm} / \mathrm{h}^{2}$ is a key point of the flood recession process. The following example shows what $V i=0.2 \mathrm{~mm} /$ $\mathrm{h}^{2}$ means: According to China's National Meteorological Center, ${ }^{2}$ a rain event exceeding $15 \mathrm{~mm}$ per $12 \mathrm{~h}$ could be called a heavy rain. A rainfall event with a uniform decrease in rain intensity at a total rainfall depth of $15 \mathrm{~mm}$ within $12 \mathrm{~h}$ (its rainfall intensity decreases from 2.5 to 0 in $12 \mathrm{~h}$ ) is a rainfall event with $V i=0.2 \mathrm{~mm} / \mathrm{h}^{2}$. Our conclusion, therefore, indicates that when heavy rain occurs in a basin, the flood recession process in the river basin is no longer affected by rainfall factors, but controlled by underlying surface factors, which is consistent with Hua and Wen (1980).

\footnotetext{
$\overline{2}$ http://www.cma.gov.cn/2011xzt/2012zhuant/20120928_1_1_1_1/ 2010052703/201212/t20121212_195616.html.
} 


\section{Conclusion}

By selecting eight watersheds in the upper mountainous area of the Huaihe River Basin, we examined the impacts of rainfall and the underlying surface on flood recession processes. The exponential equation was used to describe the flood recession processes, and it performed well for $95 \%$ of all flood recession processes, with the $R^{2}$ values higher than 0.75 .

Six factors were selected to describe the rainfall and land surface properties associated with the flood recession processes, namely decrease rate of rainfall intensity $(V i)$, distance from the storm center to the outlet of the basin $(D)$, basin area (Area), basin shape coefficient $(B s)$, basin average slope (Slope), and basin relief amplitude $(R A)$. The results of the Kendall tau test and the Spearman rank-order correlation test show that the flood recession coefficient is influenced by different factors in different $V i$. When the decrease rate of rain intensity is less than $0.2 \mathrm{~mm} / \mathrm{h}^{2}$, the relationship between rainfall and flood recession is the closest. When the decrease rate of rain intensity is higher than $0.2 \mathrm{~mm} / \mathrm{h}^{2}$, the flood recession process is most closely related to the underlying surface factors.

Backward elimination was used to compare the importance of each variable on $R$. The results show that the decrease rate of rain intensity is the most influential factor in flood recession when $V i$ is less than $0.2 \mathrm{~mm} / \mathrm{h}^{2}$. The average slope of the watershed is the most influential factor in the flood recession process when $V i$ is between 0.2 and $0.5 \mathrm{~mm} /$ $\mathrm{h}^{2}$. The area of the watershed has the greatest influence on the recession process when $V i$ is beyond $0.5 \mathrm{~mm} / \mathrm{h}^{2}$.

In summary, although both rainfall and underlying surface conditions impact flood recession processes, they play different roles in different rainfall conditions at different watersheds. We classified flood recession processes in small watersheds based on diverse rainfall characteristics and clarified the dominant factors in different categories. The results of this study are useful for determining the flood recession coefficient and could be used as a reference for flood forecasting and floodwater resource use. When heavy rain or great amount of rainfall occurs, basin slope and area will successively become the dominant factor of flood recession processes. For small watersheds with large average slopes, the recession process is very fast, and special attention should be paid to flood risk control. For large watersheds with small average slopes, however, the recession process will be slower, and more consideration should be given to the use of floodwater resources. More research is needed to further strengthen the view of this study.

Acknowledgements The research reported in this manuscript is funded by the National Key Research \& Development (R\&D) Plan (Grants No. 2016YFC0400902), the National Natural Science
Foundation of China (Grants No. 41971039), and the Youth Innovation Promotion Association CAS (No. 2017074).

Open Access This article is licensed under a Creative Commons Attribution 4.0 International License, which permits use, sharing, adaptation, distribution and reproduction in any medium or format, as long as you give appropriate credit to the original author(s) and the source, provide a link to the Creative Commons licence, and indicate if changes were made. The images or other third party material in this article are included in the article's Creative Commons licence, unless indicated otherwise in a credit line to the material. If material is not included in the article's Creative Commons licence and your intended use is not permitted by statutory regulation or exceeds the permitted use, you will need to obtain permission directly from the copyright holder. To view a copy of this licence, visit http://creativecommons. org/licenses/by/4.0/.

\section{References}

Ahmad, A., A. El-Shafie, S.F.M. Razali, and Z.S. Mohamad. 2014. Reservoir optimization in water resources: A review. Water Resources Management 28(11): 3391-3405.

Alfieri, L., P. Salamon, A. Bianchi, J. Neal, P. Bates, and L. Feyen. 2014. Advances in pan-European flood hazard mapping. Hydrological Processes 28(13): 4067-4077.

Amit, H., V. Lyakhovsk, A. Katz, A. Starinsky, and A. Burg. 2002. Interpretation of spring recession curves. Ground Water 40(5): $543-551$.

Arnell, N.W., and S.N. Gosling. 2016. The impacts of climate change on river flood risk at the global scale. Climatic Change 134(3): $387-401$.

Beck, H.E., A.I.J.M. van Dijk, D.G. Miralles, R.A.M. de Jeu, L.A. Bruijnzeel, T.R. McVicar, and J. Schellekens. 2013. Global patterns in base flow index and recession based on streamflow observations from 3394 catchments. Water Resources Research 49(12): 7843-7863.

Beven, K.J., and M.J. Kirkby. 1979. A physically based, variable contributing area model of basin hydrology. Hydrological Sciences Bulletin 24(1): 43-69.

Chang, C., and P. Feng. 2017. The impact of land use/land cover changes and hydraulic structures on flood recession process. Journal of Water and Climate Change 8(3): 375-387.

Charron, C., and T.B.M.J. Ouarda. 2015. Regional low-flow frequency analysis with a recession parameter from a non-linear reservoir model. Journal of Hydrology 524: 468-475.

Chen, G.H., W.D. Zheng, and X.D. Zheng. 2016. Analysis of flood characteristics of Sihe river in Huaihe River basin from 1991 to 2015. Harness of Huaihe River 8: 6-7 (in Chinese).

China, People's Republic of. Ministry of Water Resources. Hydrology Bureau. 2006-2015. Hydrological Data of Huaihe River Basin, Annual Hydrological Report. Beijing: China Water and Power Press (in Chinese).

Costa, M.H., A. Botta, and J.A. Cardille. 2003. Effects of large-scale changes in land cover on the discharge of the Tocantins River, Southeastern Amazonia. Journal of Hydrology 283(1-4): 206-217.

Curebal, I., R. Efe, H. Ozdemir, A. Soykan, and S. Sönmez. 2016. GIS-based approach for flood analysis: Case study of Keçidere flash flood event (Turkey). Geocarto International 31(4): 355-366.

Esposito, G., F. Matano, and G. Scepi. 2018. Analysis of increasing flash flood frequency in the densely urbanized coastline of the Campi Flegrei volcanic area, Italy. Frontiers in Earth Science 6: Article 63. 
Fan, S.X., and S.W. Han. 1991. Testing research on the effects of land surface slopes upon surface runoff. Bulletin of Soil and Water Conservation 11(4): 6-10 (in Chinese).

Gottschalk, L., and R. Weingartner. 1998. Distribution of peak flow derived from a distribution of rainfall volume and runoff coefficient, and a unit hydrograph. Journal of Hydrology 208(3-4): 148-162.

Guan, L., L. Wen, D.D. Feng, H. Zhang, and G.C. Lei. 2014. Delayed flood recession in central Yangtze floodplains can cause significant food shortages for wintering geese: Results of inundation experiment. Environmental Management 54(6): 1331-1341.

Hua, S., and K. Wen. 1980. A study on the mathematical model of watershed flow concentration (II). Journal of Hydraulic Engineering 6: 1-13 (in Chinese).

Jin, Y., W.P. Zhang, J.T. Liu, and G.Q. Wu. 2017. Relation analysis of topographic index and flood recession characteristics. Yangtze River 48(13): 23-25 (in Chinese).

Karlsen, R.H., K. Bishop, T. Grabs, M. Ottosson-Lofvenius, H. Laudon, and J. Seibert. 2019. The role of landscape properties, storage and evapotranspiration on variability in streamflow recessions in a boreal catchment. Journal of Hydrology 570: 315-328.

Kendall, M.G. 1938. A new measure of rank correlation. Biometrika 30(1-2): 81-93.

Khaleghi, M., V. Gholami, J. Ghodusi, and H. Hosseini. 2011. Efficiency of the geomorphologic instantaneous unit hydrograph method in flood hydrograph simulation. Catena 87(2): 163-171.

Kim, K.B., and D. Han. 2017. Exploration of sub-annual calibration schemes of hydrological models. Hydrology Research 48(4): 1014-1031.

Krakauer, N.Y., and M. Temimi. 2011. Stream recession curves and storage variability in small watersheds. Hydrology and Earth System Sciences 15(7): 2377-2389.

Li, J.Z., and P. Feng. 2011. The effects of underlying surface change on floods in Zijingguan watershed. Geographical Research 30(5): 921-930 (in Chinese).

Li, J.Z., P. Feng, and Y. Wang. 2010. Recession law of groundwater flow. Journal of Tianjin University 43(5): 400-405. (in Chinese).

Li, F.D., X.F. Song, C.M. Liu, J.J. Yu, C. Yang, X.C. Liu, K. Hu, and C.Y. Tang. 2006. Discharge recession from runoff plots in representative mountain area in north China. Journal of Beijing Forestry University 28(2): 79-84 (in Chinese).

Liu, P., L. Li, S. Guo, L. Xiong, W. Zhang, J. Zhang, and C-Y. Xu. 2015. Optimal design of seasonal flood limited water levels and its application for the Three Gorges Reservoir. Journal of Hydrology 527: 1045-1053.

Maillet, E. 1905. Essais d'hydraulique souterraine et fluviale. Nature 72(1854): 25-26.

Mishra, S., C. Saravanan, V. Dwivedi, and K. Pathak. 2014. Discovering flood recession pattern in hydrological time series data mining during the post monsoon period. International Journal of Computer Applications 90(8): 35-44.

Norbiato, D., M. Borga, M. Sangati, and F. Zanon. 2007. Regional frequency analysis of extreme precipitation in the eastern Italian Alps and the August 29, 2003 flash flood. Journal of Hydrology 345(3-4): 149-166.

Patnaik, S., B. Biswal, D.N. Kumar, and B. Sivakumar. 2018. Regional variation of recession flow power-law exponent. Hydrological Processes 32(7): 866-872.

Ronchail, J., J. Carlo Espinoza, G. Drapeau, M. Sabot, G. Cochonneau, and T. Schor. 2018. The flood recession period in Western Amazonia and its variability during the 1985-2015 period. Journal of Hydrology-Regional Studies 15: 16-30.

Saboe, C.W. 1966. Summer base-flow recession curves for Iowa streams. Open-file report 66-120. Reston, VA: U.S. Geological Survey.

Sampson, C.C., A.M. Smith, P.D. Bates, J.C. Neal, L. Alfieri, and J.E. Freer. 2015. A high-resolution global flood hazard model. Water Resources Research 51(9): 7358-7381.
Sayers, P.B., J.W. Hall, and I.C. Meadowcroft. 2002. Towards riskbased flood hazard management in the UK. Proceedings of the Institution of Civil Engineers-Civil Engineering 150(5): 36-42.

Shao, X.J., J. Zhang, Z.J. Wang, and S.H. Liao. 2009. Preliminary evaluation of the current level of flood water resource utilization in the Yellow River Basin. In Advance in water resources and hydraulic engineering, ed. C. Zhang, and H. Tang, 367-372. Berlin: Springer.

Shaw, S.B., T.M. McHardy, and S.J. Riha. 2013. Evaluating the influence of watershed moisture storage on variations in base flow recession rates during prolonged rain-free periods in medium-sized catchments in New York and Illinois, USA. Water Resources Research 49(9): 6022-6028.

Shorr, N. 2000. Early utilization of flood-recession soils as a response to the intensification of fishing and upland agriculture: Resourceuse dynamics in a large Tikuna community. Human Ecology 28(1): 73-107.

Shuster, W.D., Y. Zhang, A.H. Roy, F.B. Daniel, and M. Troyer. 2008. Characterizing storm hydrograph rise and fall dynamics with stream stage data. Journal of the American Water Resources Association 44(6): 1431-1440.

Song, J., J. Xia, L. Zhang, Z.-H. Wang, H. Wan, and D. She. 2016. Streamflow prediction in ungauged basins by regressive regionalization: A case study in Huai River Basin, China. Hydrology Research 47(5): 1053-1068.

Spearman, C. 1904. The proof and measurement of association between two things. American Journal of Psychology 1: 72-101.

Tallaksen, L.M. 1995. A review of baseflow recession analysis. Journal of Hydrology 165(1-4): 349-370.

Wittenberg, H. 1999. Baseflow recession and recharge as nonlinear storage processes. Hydrological Processes 13(5): 715-726.

Wu, Y.X., H.M. Yao, G.X. Wang, G.C. Shen, R. Shi, and B.D. Hou. 2011. Analysis on characteristics of extreme drought and flood events in Huaihe River Basin. Hydro-Science and Engineering 4: 149-153 (in Chinese).

Yan, C., and W. Zhang. 2014. Effects of model segmentation approach on the performance and parameters of the Hydrological Simulation Program-Fortran (HSPF) models. Hydrology Research 45(6): 893-907.

Ye, R.H., Y. He, S.C. Yu, and Z.Y. Song. 2019. Effects of recent morphodynamic evolution on flood regimes in the Pearl River Delta. Natural Hazards 96(3): 1091-1119.

Young, P., and K. Beven. 1991. Computation of the instantaneous unit hydrograph and identifiable component flows with application to two small upland catchments-comment. Journal of Hydrology 129(1-4): 389-396.

Zhai, R., G.Q. Wang, S.C. Wan, H. Li, and C.S. Liu. 2015. Recession characteristics and process simulation of storm flood in Qingliu River. Journal of Water Resources \& Water Engineering 26(3): 1-4 (in Chinese).

Zhang, Y.L., H.E. Li, X.C. Zhang, and B. Xiao. 2007. Research of recession flow on the loess slope and its nitrogen pollution. Journal of Xi'an Unviersity of Architexture \& Technology (Natural Science Edition) 39(1): 66-71, 77 (in Chinese).

Zhang, B.B. 2019. Comparative analysis of "June 27" and "August 17 " rainstorms and floods in 2018 of the middle reaches of Huaihe river-A case study of Wujiadu hydrological station. Harness of Huaihe River 8: 10-12 (in Chinese).

Zhang, S.F., C.M. Liu, J. Xia, G. Tan, L. Li, C.T. Liu, H.Q. Zhou, and L. Guo. 2005. Indoor imitation experimental study on driving factors of rainfall-runoff process. Science in China Series D: Earth Sciences 48(3): 417-428.

Zillgens, B., B. Merz, R. Kirnbauer, and N. Tilch. 2007. Analysis of the runoff response of an alpine catchment at different scales. Hydrology and Earth System Sciences 11(4): 1441-1454. 